\title{
Modification by early experience of the tendency toward gregariousness in rats'
}

\author{
Sachio Ashida \\ THE UNIVERSITY OF MICHIGAN
}

\begin{abstract}
Abstraet
After they were weaned, albino rats were housed individually (Group 1), in pairs (Group 2), and in groups of five (Group 3). After 18 weeks of housing under these circumstances, the tendency toward gregariousness, defined as a function of the number of approaches to the other rat of the same species, was tested. Group 3 showed the strongest tendency toward gregariousness, Group 2 a weaker tendency, and Group 1 the weakest.

\section{Introduction}

Some research evidence (Denenberg, 1963; McClelland, 1956) has shown that the body weight and emotional behavior of rats are significantly influenced by their early experience. Other research evidence (Denenberg et al., 1964) has shown that the rat's behavior is affected by the postweaning social interaction with other organisms of the same species. One logical extension of these studies is to investigate the effect of postweaning social interaction of rats upon their tendency to approach another animal. The purpose of this study is to test the hypothesis that the tendency toward gregariousness is a function of rat's early experience in which the strength of such a tendency is positively related to the number of other rats housed together with the subjects in the homecage.
\end{abstract}

\section{Method}

The subjects were 30 male and 30 female SpragueDawley albino rats. One male and one female rat were used as the goal object of these subjects. The apparatus used was a commercial Jenkins-Warden Obstruction Box.

After being weaned at the age of 21 days, 10 male and 10 female rats were placed alone in individual steel cages $7 \times 8 \times 11$ in (Group 1). Ten male and 10 female rats were placed in pairs of the same sex in steel cages $9 \times 9 \times 15$ in (Group 2). Ten male and 10 female rats were placed in groups of five of the same sex in steel cages $18 \times 12 \times 20$ in (Group 3). During a period of 18 weeks after all rats were weaned, body weights and the amounts of food and water intakes were recorded twice a day.

For the experimental trials, each group was further divided into two subgroups of five rats of the same sex. One of these subgroups was designated as the experimental group and the other as the control group. Each subject was placed at the starting compartment of the obstruction box; then the plastic door of the compartment was opened in order to allow the subject to cross the narrow passway to the goal compartment via the transparent oneway-swing door. If the subject entered the goal compartment, it was allowed to stay there for $15 \mathrm{sec}$, and then was returned to the starting compartment by the experimenter. This procedure was repeated during a $10 \mathrm{~min}$. period. For the experimental group, a rat of the same sex was placed at the goal compartment. For the control group, no rat was placed at the goal compartment.

\section{Results and Diseussion}

The mean number of crossings to the goal compartment is summarized in Table 1 . An analysis of variance yields $F(1,48)=26.389$ for between Sex, $F(1,48)=7.003$ for between experimental and control Condition, and $F(2$, $48)=12.281$ for between Groups. These differences are significant beyond the $.001, .05$, and .001 level of confidence respectively. Of particular interest is the Sex by Condition interaction, $F(1,48)=5.948$, and the Groups by Condition interaction, $F(2,48)=4.869$. Both interactions are significant beyond .05 level, but the Sex by Groups interaction, $F(2,48)=2.640$, is negligible.

Interpretation of the obtained mean number of crossings is, however, complicated by the fact that each group has had different environmental conditions during the preceding 18 weeks. In order to compute the net strength of the tendency toward gregariousness, the logarithmic transformations of the number of crossings will be applied. The rational basis is as follows: It is assumed that all three groups of rats have developed different sets of response tendencies during the 18 weeks of housing. Let $T_{1}, T_{2}$, and $T_{3}$ be the set of response tendencies of the rats in Group 1, Group 2, and Group 3 respectively. The components of $T_{1}$, for example, may be a tendency to move toward the corner of the cage, to move away from a certain object in the cage, to stay with another rat, to explore the inside of the cage, and so forth. In the experimental situation, some of these tendencies may be elicited by the environmental conditions, and some may notbe elicited. Let $\mathrm{T}_{1 \mathrm{~g}}$ be the approach tendency toward the other rat in Group $1, \mathrm{~T}_{1 \mathrm{a}}$ the exploratory tendency to a new situation in Group 1 ,

Table 1. The mean Number of Crossings to Achieve Goal Compartment

\section{Groups}

Sex Conditions Group 1 Group 2 Group 3

$\begin{array}{llrrr}\text { Male } & \text { Experimental } & 1.0 & 6.0 & 3.8 \\ & \text { Control } & 3.4 & 4.4 & 2.6 \\ \text { Female } & \text { Experimental } & 4.0 & 9.8 & 11.6 \\ & \text { Control } & 3.6 & 6.8 & 5.2\end{array}$


and $\left\{T_{1 x}\right\}$ a set of unspecifiable tendencies of the rats in Group 1. Then, any possible response evocation, $R$, of the rats in Group 1 is assumed to be a function of these variables, i.e., $R=F\left(T_{1 a}, T_{1 g},\left\{T_{1 x}\right\}\right)$.

Let $m_{1}\left(R_{E i}\right)$ represent the number of crossings of ith experimental rat in Group 1 such that $R_{E i}$ is a specified component of $R, i=1,2 \ldots, 5$, and $m_{1}\left(R_{C i}\right)$ the number of crossings of ith control rat in Group 1 . And assume each component of $\mathrm{T}_{1}$, i.e., $\mathrm{T}_{1 \mathrm{a}}, \mathrm{T}_{1 \mathrm{~g}}$, and $\left\{\mathrm{T}_{1 \mathrm{x}}\right\}$, is independent of each other. Then from the above assumptions,

$$
m_{1}\left(R_{E i}\right)=f\left(T_{1 a i}\right) \cdot f\left(T_{1 g i}\right) \cdot f\left(\left\{T_{1 x i}\right\}\right) .
$$

However, in the experimental situation, the environmental condition for the control group is quite different from the condition for the experimental group, i.e., a rat was placed in the goal compartment for the experimental group, but no rat was placed for the control group. Thus, for the control group, we have

$$
m_{1}\left(R_{C i}\right)=f\left(T_{1 a i}\right) \cdot f\left(\left\{T_{1 x i}\right\}\right) \text {. }
$$

In order to factorize the net strength of the tendency toward gregariousness, i.e., $f\left(\mathrm{~T}_{1 \mathrm{gi}}\right)$, take logarithm of (1) and (2), and subtract (2) from (1). We have

$$
\log m_{1}\left(R_{E i}\right)-\log m_{1}\left(R_{C i}\right)=\log f\left(T_{1 g i}\right) \text {. }
$$

The mean strength of the tendency toward gregariousness, $1 / \mathrm{n} . \sum_{i}^{n} \log \mathrm{f}\left(\mathrm{T}_{1 \mathrm{gi}}\right)$, can be computed easily from the equation (3). The data analysis of this type seems to have a certain advantage in which the main effect of the experiment in question could be evaluated (see Fig. 1).

The results show that the relative strength of the tendency toward gregariousness is clearly a function of the number of members housed in the homecage. It appears that at least some of the necessary conditions fostering such a functional relationship are effective early in the living conditions of the rats and that the tendency toward gregariousness can be acquired. The results also show that the differences between groups of the same sex in the body weight, the rate of weight gain, and the mean amounts of food and water intake during the 18 weeks of housing were not statistically significant.

Effects of early experience on the tendency toward gregariousness seem to be much more complex and extensive in rats than in birds or fishes. Collias (1952), for example, found that hand-reared chicks respond very slowly to the food-call chucking of the hen. Qualitative measure of approach tendency of isolated chick to another chick revealed that the approach was much slower than normal. When they were placed with the flock, such chicks tended to keep apart from the group

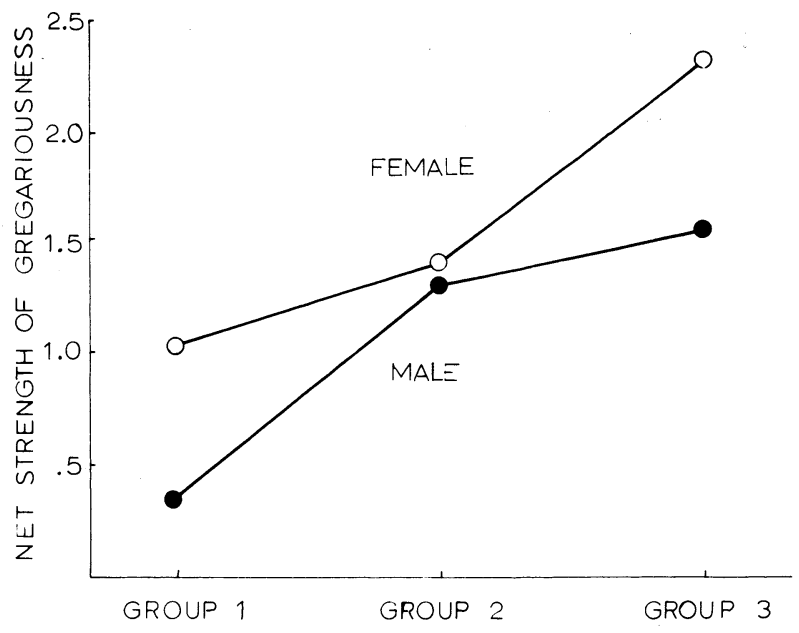

Fig. 1. The net strength of the tendency toward gregariousness as a function of the number of rats housed together in their homecage. The n et strength is shown in terms of Antilogarithm of the equation (4).

(e.g., Collias, 1950). The results of the present study, however, clearly confirm our general hypothesis that the strength of the tendency toward gregariousness is a function of early experience. In summary, it is possible to estimate the net strength of.such a tendency by use of a logarithmic transformation of the obtained data and by a simple computation of the following equation

$$
\begin{aligned}
& 1 / n .{ }_{\log } f\left(T_{j g i}\right)= \\
& 1 / n . \Sigma n_{i}^{n} \log m_{j}\left(R_{E i}\right)-1 / n ._{i}^{n} \log m_{j}\left(R_{C i}\right)
\end{aligned}
$$

where $\mathrm{j}$ is the code number of a specified group of rats.

\section{Referenees}

COLLIAS, N. E. Social life and the individual among vertebrate animals. Ann. N. Y. Acad. Sci., 1950,51, 1074-1092.

COLLIAS, N. E. The development of social behavior in birds. Auk. , 1952, 69, 127-159.

DENENBERG, V. H. Early experience and emotional development. Scient. Amer., 1963, 208, 138-146.

DENENBERG, V. H., HUDGENS, G. A., \& ZARROW, M. X. Mice reared with rats: Modification of behavior by early experience with another species. Science, $1964,143,380-381$.

MCCLELLAND, W. J. Differential handling and weight gain in the albino rat. Canad.J.Psychol., 1956, 10, 19-22.

\section{Note}

1. The author wishes to thank Mr. Keene Hueftle, University of Nebraska, for his laboratory assistance. 